\title{
Intensive plaque modification with rotational atherectomy and cutting balloon before drug-eluting stent implantation for patients with severely calcified coronary lesions: a pilot clinical study
}

Qiyong $\mathrm{Li}^{1,2+}$, Yong $\mathrm{He}^{1+}$, Li Chen ${ }^{3}$ and Mao Chen ${ }^{1 *}$

\begin{abstract}
Background: This study investigated whether, for patients with severely calcified coronary lesions, use of a cutting balloon (CB) during rotational atherectomy (RA) before placing a drug-eluting stent will improve periprocedural outcomes, compared to RA with a conventional plain balloon.

Methods: In a randomized controlled trial, patients with severely calcified lesions of calcium arc $\geq 180^{\circ}$ were apportioned to receive intensive plaque modification with $\mathrm{RA}$ and $\mathrm{CB}(\mathrm{RA}+\mathrm{CB} ; n=35)$ or RA with conventional plain balloon (RA; $n=36)$. Intravascular ultrasound was applied for quantitative or qualitative analyses of percutaneous coronary intervention outcomes. The primary outcome was acute lumen gain after drug-eluting stent. Results: The RA $+C B$ and RA groups were similar in baseline mean arcs of superficial calcium, and minimum lumen cross-sectional areas (CSAs). The mean minimum stent CSA after percutaneous coronary intervention (PCl) of the RA + $\mathrm{CB}$ group $\left(5.9 \pm 1.7 \mathrm{~mm}^{2}\right)$ was significantly larger than that of the RA group $\left(5.0 \pm 1.4 \mathrm{~mm}^{2} ; P=0.021\right)$. Patients in the $\mathrm{RA}+\mathrm{CB}$ group achieved significantly larger acute CSA gain after $\mathrm{PCl}\left(4.5 \pm 1.5 \mathrm{~mm}^{2}\right)$ relative to the RA group ( $3.8 \pm 1$. $5 \mathrm{~mm}^{2} ; P=0.035$ ). The groups were similar in rates of periprocedural complications, but at the 1-year follow-up the RA $+\mathrm{CB}$ had a lower rate of revascularization for restenosis of the target vessel and MACE (5.7\%) than did the RA group $(22.2 \%, P=0.046)$.
\end{abstract}

Conclusion: Aggressive plaque preparation with RA and CB seems to be safe and effective for patients with severely calcified coronary lesions.

Trial registration: Current Controlled Trials ChiCTR-INR-16008274. Retrospectively registered 12 April 2016.

Keywords: Coronary calcification, Rotational atherectomy, Cutting balloon, Randomized controlled trial

\section{Background}

Calcification of the coronary lesion is a clinically important characteristic of coronary atherosclerosis that responds poorly to conventional percutaneous coronary intervention (PCI) $[1,2]$. Indeed, severely calcified coronary lesions are challenging for interventional

\footnotetext{
* Correspondence: hmaochen@vip.sina.com

${ }^{\dagger}$ Equal contributors

'Department of Cardiology, West China Hospital, Sichuan University,

Chengdu, China

Full list of author information is available at the end of the article
}

cardiologists during the PCI process since they can cause the balloon dilation to fail and subsequent incomplete and asymmetrical stent expansion [3, 4]. Calcified coronary lesions are also associated with increased risk of adverse events after PCI, such as stent restenosis and thrombosis [5-8]. Thus, coronary calcification warrants the development of further treatment strategies for patients with these lesions.

During the past few decades, many novel devices and techniques have been proposed to treat severely calcified coronary lesions $[9,10]$. The results of early observational 
studies and clinical trials suggested that modification of severely calcified coronary lesions with rotational atherectomy (RA) may ease the process of angioplasty and PCI $[11,12]$. Other clinical trials indicated that pre-modification of the calcified coronary lesions with RA improved acute periprocedural outcomes, such as acute gain of the lumen $[13,14]$, with relatively few major adverse cardiovascular events (MACE) [15]. In view of this, the guidelines for PCI of the 2011 American Heart Association, and the American College of Cardiology, recommend RA as an optional therapy for patients with severely calcified coronary lesions (Class IIa) [16]. Moreover, to further improve the clinical application of RA, a standardized protocol has recently been published by a European expert consensus [17]. However, a clinical trial published in 2013 called into question the benefit of routine lesion preparation using RA, as it was not associated with an improved mid-term clinical outcome [18]. RA may not be adequate for some patients with severe coronary calcification.

The cutting balloon (CB) has been proposed as a treatment for calcified coronary lesions, but clinical evidence is limited to a few case reports $[19,20]$ or observational studies [21]. The application of the CB for angioplasty has proved successful for treating hemodialysis access stenosis, and the 6-month patency achieved with the $\mathrm{CB}$ was significantly higher compared with balloon angioplasty [22]. These facts suggest that in cases of severely calcified coronary lesions, plaque modification with both RA and CB before drug-eluting stent implantation may improve the PCI. Although a retrospective study implied that RA combined with $\mathrm{CB}$ could have a favorable role in lesion preparation [23], to the best of our knowledge, there have been no relevant randomized controlled trials published.

Therefore, we conducted a pilot randomized controlled trial to evaluate the efficacy and safety of intensive plaque modification with $\mathrm{RA}$ and $\mathrm{CB}$ angioplasty before placement of a drug-eluting stent, relative to that of RA with a plain conventional balloon. The periprocedural outcomes of patients with severely calcified coronary lesions were confirmed on intravascular ultrasound (IVUS).

\section{Methods}

\section{Patients and study protocol}

This study was designed as a two-center open-label randomized controlled study to evaluate the safety and efficacy of RA combined with cutting balloon (CB) angioplasty, relative to conventional balloon angioplasty (BA), for plaque modification before the implantation of drug-eluting stents for patients with severely calcified coronary lesions. The ethics committees of People's Hospital of Sichuan Province and West China Hospital of Sichuan University, China, approved the study protocol. All patients provided signed informed consent before the PCI, and the patients were free to withdraw from the study for any reason at any stage.

\section{Inclusion and exclusion criteria}

From January 2010 to September 2014, at the Cardiovascular Departments of the People's Hospital of Sichuan Province and West China Hospital of Sichuan University, China, we evaluated 80 consecutive patients with 80 severely calcified coronary lesions who were scheduled for RA, CB, or both prior to PCI and drug-eluting stent implantation. These patients met the following inclusion criteria of the study: with at least one severe coronary stenosis $\geq 70 \%$, as indicated by angiography; with at least one severely calcified lesion of the target vessels, defined as a calcium arc of $\geq 180^{\circ}$ [24]; and agreed to receive an $\mathrm{RA}$ or CB-based intensive modification of the plaque before PCI.

Patients were excluded from the current study for any of the following: acute thrombosis with unstable hemodynamic status requiring emergent PCI; previous PCI and presence of in-stent restenosis; extremely tortuous or angulated lesions or lesions with dissection before balloon expansion; lesion within a vein graft; or other complications or comorbidities which were contraindicated for angiography or PCI (e.g., severe renal dysfunction).

\section{Randomization and treatment strategies}

The included patients were randomized to either of 2 groups based on plaque modification strategies: pretreatment of the severely calcified plaque with RA and subsequent $\mathrm{CB}$ (RA + CB group); or pretreatment with RA and conventional plain balloon (RA group). The randomization was performed according to a random sequence generated by a computer program. No blinding was adopted in this study. The PCI procedures and the IVUS examinations were performed by a group of experienced physicians of interventional cardiology.

\section{$\mathrm{PCl}$ procedures}

After confirmation of the diagnosis of coronary heart disease, all of the included patients were pretreated with aspirin or clopidogrel. A 300-mg loading dose of clopidogrel was administered before the procedure if patients were not pretreated. If they were considered to have a heavy thrombotic burden, periprocedural glycoprotein IIb/IIIa inhibitors were used, at the operator's discretion.

During interventions, intravenous unfractionated heparin $(100 \mathrm{IU} / \mathrm{kg})$ was administered to maintain activated clotting time $\geq 300 \mathrm{~s}$. A digital cardiovascular Artis zee III ceiling-mounted Siemens system was applied for the angiographic and PCI process. The choice of interventional strategy and size of the sirolimus drug-eluting 
stent were left to the discretion of the same operator for all patients.

An oral antiplatelet therapy regimen was implemented in accordance with the current guidelines, i.e., a combination of aspirin and clopidogrel at least 12 months for drug-eluting stent $[16,25]$. After the PCI, cardiovascular medications were prescribed depending on the comorbidities of the patients, and the post-procedural medical therapy often included aspirin, clopidogrel, statin, betablocker, angiotensin-converting enzyme-inhibitors, and angiotensin-receptor blockers.

\section{Description of RA and CB processes}

For patients in the RA $+\mathrm{CB}$ group, we pretreated severely calcified plaque with $R A$, and then subsequently with RA, with pre-dilation of the lesion achieved with a CB. As for patients randomized to the RA group, the calcified lesion was pretreated with RA but only a conventional plain balloon was selected for subsequent predilation.

RA was performed with a burr size of $1.25,1.50$, or $1.75 \mathrm{~mm}$, and was selected to reach a burr/vessel ratio of 0.5 (maximum: 0.7 if needed). The rotational speed of the burr ranged from 140,000 to 180,000 rotations per minute. The burr was platformed immediately proximal to the lesion to avoid injury to the healthy vessel segment. Intracoronary heparin and nitroglycerin were used to prevent any slow-flow occurring during or after RA.

For patients in both groups, the diameter of the $\mathrm{CB}$ or the plain conventional balloon selected for pre-dilatation was $\leq 0.5 \mathrm{~mm}$ that of the planned stent size, based on the vessel media-to-media diameters determined by IVUS. Stents were deployed after confirmation of full balloon expansion. Non-compliant balloon postdilatation after stenting was considered when IVUS revealed poor stent expansion.

\section{IVUS procedures}

After conventional coronary angiography, IVUS was performed at the baseline timepoint and repeated immediately after stent implantations in all cases. The IVUS examinations were performed using a Boston Scientific image processor iLab Ultrasound Imaging System. Briefly, the IVUS catheter was carefully advanced distal to the culprit lesion under fluoroscopic guidance, and was then withdrawn automatically at $0.5 \mathrm{~mm} / \mathrm{s}$ to perform the imaging sequence, which started $20 \mathrm{~mm}$ distal to the lesion and ended at the aorto-ostial junction. For those patients with severely narrow lesions in which IVUS could not access the distal segment even after predilatation, the minimum lumen cross-sectional area (CSA) was estimated as the lumen CSA of the arrival section.

\section{IVUS analysis}

Off-line IVUS analyses were performed with the use of Planimetry software (echoPlaque 3.0, Indec Systems). Quantitative IVUS measurements included the diameters and the CSA of the stent and the external elastic membrane. The IVUS measurements were evaluated based on the American College of Cardiology Clinical Expert Consensus Document on Standards for Acquisition, Measurement, and Reporting of Intravascular Ultrasound Studies [26].

After stent implantation, we measured the minimum stent CSA, and the acute lumen gain was estimated as the minimum intra-stent CSA after stenting minus the minimum CSA before stenting.

\section{Outcomes and clinical follow-up of the patients}

The primary outcome of the study was the acute lumen gain of the patients in the 2 groups. Also analyzed were the RA-associated periprocedural rates of successful stent implantation and periprocedural complications (including coronary dissection, coronary perforation, coronary slow flow or no-reflow, stent thrombosis, and stent dislodgment), balloon dilation, and PCI.

The patients were followed for at least one year after the PCI, and another angiographic examination was performed. Major adverse cardiovascular events (MACE) were documented including death, myocardial infarction, and target vessel revascularization. Death included allcause mortality. Myocardial infarction was defined according to current guidelines [27]. Target vessel revascularization was defined as revascularization during the follow-up period due to restenosis, either within the target lesion or within the same coronary artery.

\section{Statistical analyses}

Continuous data are presented as the mean \pm standard deviation and the categorical data are presented as number and percentage. Each set of data was subjected to a test for normal distribution. Differences in the continuous and categorical data between the 2 groups were analyzed using Student's $t$-test or chi-squared analysis. Statistical analyses were achieved with SPSS 16.0 software (SPSS, Chicago, IL, USA). A $P$-value $<0.05$ was considered statistically significant.

\section{Results}

\section{Demographic and clinical baseline characteristics of the patients}

Initially, 80 patients with coronary heart disease with severely calcified lesions in the target arteries and scheduled to receive a selective PCI were enrolled in the study, and were apportioned equally to the $\mathrm{RA}+\mathrm{CB}$ group or the RA group. However, 5 patients in the RA + $\mathrm{CB}$ group and 4 patients in the RA group later withdrew 
from the study, for personal reasons. Finally, 71 patients (35 in the RA + CB group and 36 in the RA group) were included in the current analyses.

The mean age of the patients was 71.5 years, and there were 50 men and 21 women (Table 1). All of the included patients successfully underwent the IVUS examination and PCI, and were followed for at least 1 year. The RA + CB and RA groups were similar for baseline characteristics including age, gender, coronary heart disease diagnosis and risk factors, comorbidities and past history of PCI and coronary artery bypass graft $(P>0.05$, all), except that the prevalence of chronic kidney disease was significantly higher in the RA + CB group (28.6\%) than in the RA group $(8.3 \% ; P=0.027)$.

\section{Coronary lesions and the $\mathrm{PCl}$ procedures}

The RA + CB and the RA groups were well matched for the numbers of affected arteries, the prevalence of bifurcated, ostial, and chronic total occlusions, and the Medina classifications of the bifurcated lesions (Table 2). However, the percentage of patients with a left main arterial lesion was significantly higher in the $\mathrm{RA}+\mathrm{CB}$ group (22.9 \%) than the RA group (5.6 \%, $P=0.036$ ). The two groups were also similar with regard to reference vessel diameter, minimal lumen diameter, total lesion length, and calcium length ratio, as evaluated by IVUS before PCI (Table 3).

All of the included patients received modification of the calcified lesions with RA, and the two groups were not significantly different with regard to the final burr size, or the burr-to-artery ratio (Table 2). After RA, pre- dilations of the lesions were performed in patients of the $\mathrm{RA}+\mathrm{CB}$ and RA groups with $\mathrm{CB}$ and conventional plain balloons, respectively. Balloon underexpansion was adequately resolved since repeated RA was performed in patients with balloon underexpansion, and no residual balloon underexpansion existed for the included patients in either group. No significant difference was detected for maximal balloon diameters, maximal balloon inflation pressures, or mean balloon inflation time for patients randomized to the two groups (Table 2).

All of the patients in both groups received successful stent delivery. Similarly, the two groups were matched for mean stent diameters, lengths, and stent release pressures (Table 3). The two groups were comparable for the proportions of patients who received postdilations with non-compliant balloons, the maximal balloon inflation pressures, and the mean balloon inflation time (Table 2).

\section{Gain in acute CSA after PCI}

The IVUS-evaluated mean arc of superficial calcium and baseline minimum lumen CSA of the RA + CB group $\left(288.1 \pm 36.3^{\circ}\right.$ and $1.3 \pm 0.4 \mathrm{~mm}^{2}$, respectively) were statistically similar to that of the RA group $\left(279.7 \pm 47.5^{\circ}\right.$ and $1.3 \pm 0.4 \mathrm{~mm}^{2} ; P>0.05$, both; Table 3). However, the minimum stent CSA after PCI of the $\mathrm{RA}+\mathrm{CB}$ group $\left(5.9 \pm 1.7 \mathrm{~mm}^{2}\right)$ was significantly larger than that of the RA group $\left(5.0 \pm 1.4 \mathrm{~mm}^{2} ; P=0.021\right)$. More importantly, patients in the $\mathrm{RA}+\mathrm{CB}$ group achieved a significantly larger acute CSA gain after PCI $\left(4.5 \pm 1.5 \mathrm{~mm}^{2}\right)$ than did

Table 1 Baseline demographic clinical characteristics of patients in the RA + CB and RA (control) groups

\begin{tabular}{|c|c|c|c|c|}
\hline & & $R A+C B$ & RA & $P$ \\
\hline \multicolumn{2}{|l|}{ Subjects, $n$} & 35 & 36 & \\
\hline \multirow[t]{3}{*}{ Demographics } & Age, y & $69.3 \pm 11.6$ & $72.2 \pm 10.2$ & 0.269 \\
\hline & Male, n (\%) & $25(71.4)$ & $25(69.4)$ & 0.855 \\
\hline & Body mass index, $\mathrm{kg} / \mathrm{m}^{2}$ & $26.2 \pm 4.9$ & $24.8 \pm 4.1$ & 0.184 \\
\hline \multirow[t]{3}{*}{ Diagnosis, n (\%) } & Stable angina & $7(20.0)$ & $6(16.7)$ & 0.717 \\
\hline & Unstable angina & $26(74.3)$ & $28(77.8)$ & 0.730 \\
\hline & Acute myocardial infarction & $2(5.7)$ & $2(5.6)$ & 0.977 \\
\hline \multirow[t]{6}{*}{ Risk factors, n (\%) } & Diabetes mellitus & $25(71.4)$ & $27(75.0)$ & 0.734 \\
\hline & Hypertension & $27(77.1)$ & $28(77.8)$ & 0.949 \\
\hline & Current smokers & $20(57.1)$ & $22(61.1)$ & 0.734 \\
\hline & Dyslipidemia & $18(51.4)$ & $20(55.6)$ & 0.727 \\
\hline & Chronic kidney disease & $10(28.6) *$ & $3(8.3)$ & 0.027 \\
\hline & LVEF $<50 \%$ & $14(40.0)$ & $16(44.4)$ & 0.705 \\
\hline \multirow[t]{3}{*}{ Past history, n (\%) } & Myocardial infarction & $8(22.9)$ & $10(27.8)$ & 0.738 \\
\hline & $\mathrm{PCl}$ & $5(14.3)$ & $6(16.7)$ & 0.782 \\
\hline & Coronary artery bypass graft & $0(0)$ & $0(0)$ & - \\
\hline
\end{tabular}

${ }^{*} P<0.05$ compared with RA group 
Table 2 Characteristics of coronary lesions and PCl procedures of patients in the RA + CB and RA (control) groups*

\begin{tabular}{|c|c|c|c|c|}
\hline & & $R A+C B$ & RA & $P$ \\
\hline \multicolumn{2}{|l|}{ Subjects, $n$} & 35 & 36 & \\
\hline \multirow[t]{8}{*}{ Lesion location, n (\%) } & Left main coronary artery & $8(22.9) *$ & $2(5.6)$ & 0.036 \\
\hline & Left anterior descending artery & $20(57.1)$ & $23(63.9)$ & 0.561 \\
\hline & Left circumflex artery & $5(14.3)$ & $4(11.1)$ & 0.688 \\
\hline & Right coronary & $7(20.0)$ & $9(25.0)$ & 0.614 \\
\hline & Ostial lesion & $3(8.6)$ & $4(11.1)$ & 0.720 \\
\hline & Chronic total occlusion & $0(0)$ & $0(0)$ & - \\
\hline & Bifurcated lesion (Medina 1, 1, 1) & $11(31.4)$ & $14(38.9)$ & 0.511 \\
\hline & Bifurcated lesion (Medina 1, 1, 0) & $2(5.7)$ & $2(5.6)$ & 0.977 \\
\hline \multirow[t]{4}{*}{ Indications for RA } & Balloon catheter not passed, n (\%) & $20(57.1)$ & $22(61.1)$ & 0.275 \\
\hline & Balloon catheter under expansion, n (\%) & $15(42.9)$ & $14(38.9)$ & 0.327 \\
\hline & Final bur size, mm & $1.58 \pm 0.15$ & $1.51 \pm 0.18$ & 0.100 \\
\hline & Burr/artery ratio & $0.56 \pm 0.03$ & $0.56 \pm 0.04$ & 0.934 \\
\hline \multirow[t]{4}{*}{ Pre-dilatation after RA } & Pre-dilatation, n (\%) & $35(100)$ & $36(100)$ & 1.000 \\
\hline & Max balloon diameter, mm & $2.65 \pm 0.31$ & $2.53 \pm 0.37$ & 0.163 \\
\hline & Max balloon inflation pressure, atm & $13.8 \pm 1.3$ & $14.1 \pm 1.0$ & 0.190 \\
\hline & Balloon inflation time, s & $18.3 \pm 3.6$ & $19.7 \pm 4.0$ & 0.134 \\
\hline \multirow[t]{3}{*}{ Stent implantation } & Stent delivery failure, $\mathrm{n}(\%)$ & $0(0)$ & $0(0)$ & - \\
\hline & Stent diameter, mm & $2.79 \pm 0.29$ & $2.73 \pm 0.37$ & 0.418 \\
\hline & Stent release pressure, atm & $14.5 \pm 1.5$ & $14.8 \pm 1.5$ & 0.377 \\
\hline \multirow[t]{3}{*}{ Post-dilatation after stent } & Non-compliant balloon, n (\%) & $28(82.9)$ & $31(86.1)$ & 0.188 \\
\hline & Max balloon inflation pressure, atm & $18.4 \pm 1.7$ & $18.8 \pm 2.4$ & 0.421 \\
\hline & Balloon inflation time, s & $20.4 \pm 2.9$ & $19.5 \pm 2.4$ & 0.210 \\
\hline
\end{tabular}

${ }^{*} P<0.05$ compared with RA group

Table 3 Quantitative coronary angiography (QCA) and intravascular ultrasonographic (IVUS) analyses of lesion characteristics

\begin{tabular}{|c|c|c|c|c|}
\hline & & $R A+C B$ & RA & $P$ \\
\hline & Subjects, n & 35 & 36 & \\
\hline \multirow[t]{8}{*}{ Baseline } & Total lesion length, mm & $31.3 \pm 13.6$ & $29.5 \pm 13.1$ & 0.566 \\
\hline & Calcium length ratio & $0.81 \pm 0.10$ & $0.76 \pm 0.12$ & 0.093 \\
\hline & Superficial calcium arc & $288.1^{\circ} \pm 36.3^{\circ}$ & $279.7^{\circ} \pm 41.8^{\circ}$ & 0.363 \\
\hline & Reference vessel diameter, mm & $2.8 \pm 0.3$ & $2.7 \pm 0.4$ & 0.253 \\
\hline & Min. lumen diameter, mm & $1.3 \pm 0.2$ & $1.3 \pm 0.2$ & 0.869 \\
\hline & Reference vessel CSA, $\mathrm{mm}^{2}$ & $6.4 \pm 1.5$ & $6.0 \pm 1.9$ & 0.315 \\
\hline & Min. CSA, mm² & $1.3 \pm 0.4$ & $1.3 \pm 0.4$ & 0.896 \\
\hline & Lumen stenosis rate, \% & $79.1 \pm 4.8$ & $77.8 \pm 4.2$ & 0.217 \\
\hline \multirow[t]{5}{*}{ After stent } & Total stent length per lesion, mm & $38.5 \pm 13.1$ & $35.8 \pm 12.2$ & 0.365 \\
\hline & Min. stent diameter, mm & $2.7 \pm 0.4$ & $2.5 \pm 0.4$ & 0.097 \\
\hline & Min. stent CSA, mm² & $5.9 \pm 1.7^{*}$ & $5.0 \pm 1.4$ & 0.021 \\
\hline & Residual lumen stenosis rate, \% & $10.5 \pm 10.4$ & $14.7 \pm 10.8$ & 0.103 \\
\hline & Acute CSA gain, mm² & $4.5 \pm 1.5 *$ & $3.8 \pm 1.5$ & 0.035 \\
\hline
\end{tabular}


patients in the RA group $\left(3.8 \pm 1.5 \mathrm{~mm}^{2} ; P=0.035\right)$. This suggests that RA combined with $\mathrm{CB}$ may be more effective for severely calcified lesions than RA with the conventional balloon.

\section{Periprocedural complications and follow-up results}

No patient in either group experienced periprocedural complications, including coronary perforation, stent thrombosis, or stent dislodgment (Table 4). Three patients in each group suffered from coronary slow flow or no-reflow; this rate was not significantly different between the 2 groups. Coronary dissection occurred in 3 patients in the RA $+C B$ group $(8.3 \%)$ and 4 patients in the RA group $(11.1 \%, P>0.05)$. These results suggest that modification of plaques with RA and $\mathrm{CB}$ did not carry a higher risk of periprocedural complications than RA with the conventional balloon.

After a mean follow-up of $13.2 \pm 4.7$ months, no myocardial infarction, stroke, or cardiovascular death occurred in patients of either group (Table 5). However, the percentage of patients who received revascularization for restenosis of the target vessel was significantly higher in the RA group (22.2 \%) than the RA + CB group (5.7 \%, $P=0.046$ ) by the one-year follow-up.

\section{Discussion}

This pilot randomized controlled trial evaluated the efficacy and safety of RA combined with $\mathrm{CB}$ for intensive plaque modification in patients with severely calcified coronary lesions, relative to RA with conventional balloon. We found that in these patients, RA combined with $\mathrm{CB}$ was associated with significantly greater acute CSA gain (Fig. 1), and RA and CB did not carry a higher risk of periprocedural complications during the subsequent PCI. This indicates that plaque modification with $\mathrm{RA}$ and $\mathrm{CB}$ was safe for these patients. Regarding clinical outcomes, at the 1-year follow-up the revascularization for stenosis of the target vessel, and MACE, associated with RA and $\mathrm{CB}$ was lower than that of RA with conventional balloon. This suggests that RA combined with CB may lead to a better clinical prognosis.

Table 4 Incidences of periprocedural complications of patients in the RA + CB and the RA control groups, $n(\%)$

\begin{tabular}{llll}
\hline Subjects, n & RA + CB & RA & $P$ \\
\hline Coronary dissection & 35 & 36 & \\
Coronary perforation & $3(8.3)$ & $4(11.1)$ & 0.720 \\
Coronary slow flow or no-reflow & $3(8.6)$ & $3(8.3)$ & 0.972 \\
Stent thrombosis & $0(0)$ & $0(0)$ & - \\
Stent dislodgment & $0(0)$ & $0(0)$ & - \\
\hline
\end{tabular}

Table 5 Outcomes during the 1-year follow-up of patients in the RA + CB and RA control groups, $n(\%)$

\begin{tabular}{llll}
\hline & $\mathrm{RA}+\mathrm{CB}$ & $\mathrm{RA}$ & $P$ \\
Subjects, $\mathrm{n}$ & 35 & 36 & \\
\hline Non-fatal myocardial infarction & $0(0)$ & $0(0)$ & - \\
Non-fatal stroke & $0(0)$ & $0(0)$ & - \\
Cardiovascular death & $0(0)$ & $0(0)$ & - \\
Target lesion revascularization & $2(5.7) *$ & $8(22.2)$ & 0.046 \\
MACE & $2(5.7)^{*}$ & $4(22.2)$ & 0.046 \\
\hline
\end{tabular}

${ }^{*} P<0.05$ compared with RA group

Improved acute CSA gain may be a protective factor that prevents restenosis and MACE after PCI [28]. Our results indicate that for patients with severely calcified coronary lesions, intensive plaque modification with RA and $\mathrm{CB}$ was safe, and was associated with improved immediate PCI results compared with the RA and conventional balloon. Although the potential therapeutic role of combined plaque modification with RA and $\mathrm{CB}$ for patients with severely calcified coronary lesions has been suggested in previous studies [11], to the best of our knowledge this is the first randomized controlled trial that confirms the efficacy and safety of this treatment strategy under these circumstances.

A case report published in 2004 [29] reported successful plaque modification via RA and $\mathrm{CB}$ prior to stent implantation in a 61-year-old man with severe calcified plaque in the ostium of the left circumflex of the left coronary artery. The combined RA and CB strategy facilitated optimal stent deployment. A recent retrospective cohort study [23] showed that RA prior to CB plaque modification for drug-eluting stent implantation in severely calcified lesions appeared to be more efficacious than RA with a plain balloon, with significantly larger final stent CSA. The results of our present study further confirmed the previous clinical observations that intensive plaque modification with RA and $\mathrm{CB}$ was associated with an improved acute CAS gain after PCI [23] - the combined plaque preparation strategy helped optimize the PCI, particularly the deployment of the stents in these patients with severely calcified coronary lesions.

Previous evidence showed that poor acute CSA gain after PCI may be a predictor of increased risk for long-term MACE [28]. The present study may be clinically important, since it shows that intensive plaque modification with RA and $\mathrm{CB}$ was associated with a lower risk of target lesion revascularization. However, whether combined plaque modification with RA and $\mathrm{CB}$ is associated with better long-term clinical outcomes compared with RA with a plain balloon in patients with severely calcified coronary lesions still needs to be determined in further studies.

Combined RA and CB plaque modification on acute luminal gain for these patients may be of improved 

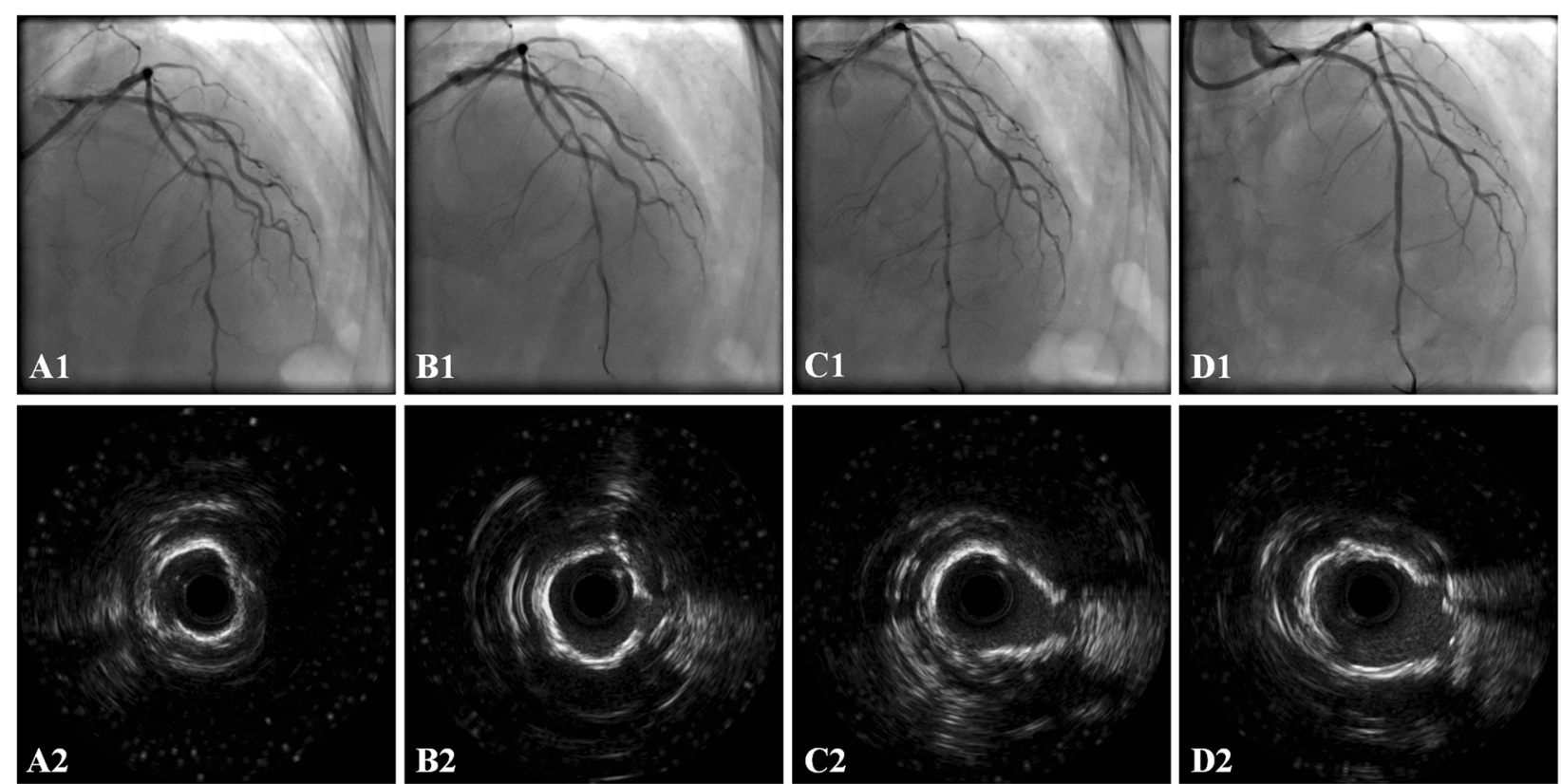

Fig. 1 The angiography and intravascular ultrasound (IVUS) images of severe coronary calcification lesion before and after rotational atherectomy, cutting balloon, and stent deployment. A1 and A2, Severe calcific stenosis of the left anterior descending artery; B1 and B2, post-rotablator; C1 and C2, post-cutting balloon; D1 and D2, post-stent

benefit, compared with RA with a plain balloon, because it overcomes the disadvantages of applying either RA or $\mathrm{CB}$ alone $[9,22]$. Pretreatment with RA can be limited by the maximum burr size $(1.75 \mathrm{~mm})$, which may be too small for some severely calcified lesions in vessels of relatively large diameter; concurrent application with CB-based plaque modification may further improve patency of these vessels. The CB catheter is relatively stiff and non-compliant, which limits its movements through lesions with sharp angulations. In the present study, use of the $\mathrm{CB}$ was associated with better-controlled predilation of the calcified lesion, which reduced the risk of extensive dissection caused by stretch of the arterial wall when using the conventional plain balloon.

Interestingly, pretreatment with RA may facilitate negotiation with the $\mathrm{CB}$ catheters, thereby enhancing the efficacy of the $C B$ technique. Plaque modification with RA and CB can optimize the deployment of the stents, although this is also dependent on the skill of the operator, to improve the acute PCI outcome and reduce the chances of early complications such as stent restenosis or thrombosis induced by stent underexpansion. Obviously, the exact mechanisms underlying the immediate benefits of combined lesion preparation with RA and $\mathrm{CB}$ deserve further investigation.

Although it has been suggested that RA and CB carries higher risks of periprocedural complications such as coronary dissection or perforation, in the present study we found that RA combined with $\mathrm{CB}$ was not associated with increased risk compared with RA with a plain balloon. Moreover, the group that received RA and CB had a lower rate of revascularization for restenosis of the target vessel and MACE during the 1-year follow-up, indicating that RA and CB may lead to better clinical prognosis.

Our study is limited in that it is a pilot clinical trial, the sample size was small, and the follow-up duration was short. Further large-scale randomized controlled trials are needed to confirm our results and explore the potential benefits of aggressive plaque modification with RA combined with CB for calcified lesions. In addition, this study was designed as an open-label trial and the baseline characteristics were not completely similar between the 2 groups. Yet, since significantly more patients in the RA + CB group had chronic kidney disease, and significantly more had lesions of the left main coronary artery, and both are known predictors of poor PCI outcomes, these imbalances did not confound the results. Finally, due to the small sample size we were unable to perform a subgroup analysis to explore whether patients with certain characteristics could benefit more from the combined plaque modification strategy. Future studies may be needed to clarify these questions.

\section{Conclusion}

This pilot randomized controlled trial indicated that aggressive plaque preparation with combined RA and $\mathrm{CB}$ seems to be safe and effective for patients with severely calcified coronary lesions, and is associated with better 
acute PCI results and clinical outcomes compared with RA with a conventional balloon. Future studies are needed to confirm our results and explore the potential long-term benefits of aggressive plaque modification with RA combined with CB for calcified lesions.

\section{Abbreviations}

CB: cutting balloon; CSAs: cross-sectional areas; IVUS: intravascular ultrasound; MACE: major adverse cardiovascular events; Min: minimum;

$\mathrm{PCl}$ : percutaneous coronary intervention; RA: rotational atherectomy.

\section{Competing interests}

The authors declare that they have no competing interests.

\section{Authors' contributions}

QL and MC designed the study. QL and YH analyzed the data and drafted the first version of the manuscript. QL, YH, and LC collected the data and critiqued the manuscript. All authors read and approved the final manuscript.

\section{Acknowledgements}

This work was supported by grants from the National Natural Science Foundation of China (Nos. 81100188) and by the Research Fund of the Sichuan Province Health Bureau, Chengdu, People's Republic of China (Nos. 110202).

\section{Author details}

${ }^{1}$ Department of Cardiology, West China Hospital, Sichuan University, Chengdu, China. '2Department of Cardiology, Sichuan Provincial People's Hospital \& Sichuan Academy of Medical Science, Chengdu, China. ${ }^{3}$ Department of Physiology, West China School of Preclinical and Forensic Medicine, Sichuan University, Chengdu, China.

\section{Received: 14 November 2015 Accepted: 9 May 2016}

Published online: 26 May 2016

\section{References}

1. Madhavan MV, Tarigopula M, Mintz GS, Maehara A, Stone GW, Genereux P. Coronary artery calcification: pathogenesis and prognostic implications. J Am Coll Cardiol. 2014;63(17):1703-14

2. Ellis SG, Vandormael MG, Cowley MJ, DiSciascio G, Deligonul U, Topol EJ, Bulle TM. Coronary morphologic and clinical determinants of procedural outcome with angioplasty for multivessel coronary disease. Implications for patient selection. Multivessel Angioplasty Prognosis Study Group. Circulation. 1990;82(4):1193-202.

3. Fitzgerald PJ, Ports TA, Yock PG. Contribution of localized calcium deposits to dissection after angioplasty. An observational study using intravascular ultrasound. Circulation. 1992;86(1):64-70.

4. Tanigawa J, Barlis P, Di Mario C. Heavily calcified coronary lesions preclude strut apposition despite high pressure balloon dilatation and rotational atherectomy: in-vivo demonstration with optical coherence tomography. Circ J. 2008;72(1):157-60

5. Fujimoto $\mathrm{H}$, Nakamura M, Yokoi $\mathrm{H}$. Impact of calcification on the long-term outcomes of sirolimus-eluting stent implantation: subanalysis of the Cypher Post-Marketing Surveillance Registry. Circ J. 2012;76(1):57-64.

6. Fujii K, Carlier SG, Mintz GS, Yang YM, Moussa I, Weisz G, Dangas G, Mehran R, Lansky AJ, Kreps EM et al. Stent underexpansion and residual reference segment stenosis are related to stent thrombosis after sirolimus-eluting stent implantation: an intravascular ultrasound study. J Am Coll Cardiol. 2005;45(7):995-8.

7. Kawaguchi R, Tsurugaya H, Hoshizaki H, Toyama T, Oshima S, Taniguchi K. Impact of lesion calcification on clinical and angiographic outcome after sirolimus-eluting stent implantation in real-world patients. Cardiovasc Revasc Med. 2008;9(1):2-8.

8. Mosseri M, Satler LF, Pichard AD, Waksman R. Impact of vessel calcification on outcomes after coronary stenting. Cardiovasc Revasc Med. 2005;6(4):147-53.

9. Mota P, de Belder A, Leitao-Marques A. Rotational atherectomy: Technical update. Rev Port Cardiol. 2015;34(4):271-8.

10. Tomey MI, Kini AS, Sharma SK. Current status of rotational atherectomy. JACC Cardiovasc Interv. 2014;7(4):345-53.
11. Tian W, Lhermusier T, Minha S, Waksman R. Rational use of rotational atherectomy in calcified lesions in the drug-eluting stent era: Review of the evidence and current practice. Cardiovasc Revasc Med. 2015;16(2):78-83.

12. Zimarino M, Corcos T, Bramucci E, Tamburino C. Rotational atherectomy: a "survivor" in the drug-eluting stent era. Cardiovasc Revasc Med. 2012;13(3):185-92.

13. Sun Y, Jiang J, Zhu G, Li C, Dong L, Liu X, Lyu L, Hu X, Xiang M, Wang J. Efficacy of intravascular ultrasound guided rotational atherectomy for heavily calcified coronary lesions. Zhonghua Xin Xue Guan Bing Za Zhi. 2014;42(7):545-50.

14. Cui JG, Yang YJ, Wu YJ, Qiao SB, Xu B, Yuan JQ, Chen J, Liu HB, You SJ, Hu FH et al. Clinical outcomes of rotational atherectomy followed by drug-eluting stenting via the transradial approach for the treatment of heavily calcified coronary lesions. Zhonghua Xin Xue Guan Bing Za Zhi. 2013;41(6):462-5.

15. Abdel-Wahab M, Baev R, Dieker P, Kassner G, Khattab AA, Toelg R, Sulimov D, Geist V, Richardt G. Long-term clinical outcome of rotational atherectomy followed by drug-eluting stent implantation in complex calcified coronary lesions. Catheter Cardiovasc Interv. 2013;81(2):285-91.

16. Levine GN, Bates ER, Blankenship JC, Bailey SR, Bittl JA, Cercek B, Chambers CE, Ellis SG, Guyton RA, Hollenberg SM et al. 2011 ACCF/AHA/SCAI Guideline for Percutaneous Coronary Intervention: a report of the American College of Cardiology Foundation/American Heart Association Task Force on Practice Guidelines and the Society for Cardiovascular Angiography and Interventions. Circulation. 2011;124(23):e574-651.

17. Barbato E, Carrie D, Dardas P, Fajadet J, Gaul G, Haude M, Khashaba A, Koch K, Meyer-Gessner M, Palazuelos J et al. European expert consensus on rotational atherectomy. Eurolntervention. 2015;11(1):30-6.

18. Abdel-Wahab M, Richardt G, Joachim Buttner H, Toelg R, Geist V, Meinertz T, Schofer J, King L, Neumann FJ, Khattab AA. High-speed rotational atherectomy before paclitaxel-eluting stent implantation in complex calcified coronary lesions: the randomized ROTAXUS (Rotational Atherectomy Prior to Taxus Stent Treatment for Complex Native Coronary Artery Disease) trial. JACC Cardiovasc Interv. 2013;6(1):10-9.

19. Asakura Y, Furukawa Y, Ishikawa S, Asakura K, Sueyoshi K, Sakamoto M, Takagi S, Takatsuki S, Oyamada K, Okabe T, et al. Successful predilation of a resistant, heavily calcified lesion with cutting balloon for coronary stenting: a case report. Cathet Cardiovasc Diagn. 1998;44(4):420-2.

20. Karvouni E, Stankovic G, Albiero R, Takagi T, Corvaja N, Vaghetti M, Di Mario C, Colombo A. Cutting balloon angioplasty for treatment of calcified coronary lesions. Catheter Cardiovasc Interv. 2001;54(4):473-81.

21. Vaquerizo B, Serra A, Miranda F, Triano JL, Sierra G, Delgado G, Puentes A, Mojal S, Brugera J. Aggressive plaque modification with rotational atherectomy and/or cutting balloon before drug-eluting stent implantation for the treatment of calcified coronary lesions. J Interv Cardiol. 2010;23(3):240-8.

22. Agarwal SK, Nadkarni GN, Yacoub R, Patel AA, Jenkins JS, Collins TJ, Annapureddy N, Kumbala D, Bodana S, Benjo AM. Comparison of cutting balloon angioplasty and percutaneous balloon angioplasty of arteriovenous fistula stenosis: a meta-analysis and systematic review of randomized clinical trials. J Interv Cardiol. 2015;28(3):288-95.

23. Furuichi S, Tobaru T, Asano R, Watanabe $Y$, Takamisawa I, Seki A, Sumiyoshi T, Tomoike H. Rotational atherectomy followed by cutting-balloon plaque modification for drug-eluting stent implantation in calcified coronary lesions. J Invasive Cardiol. 2012;24(5):191-5.

24. Hsu JT, Kyo E, Chu CM, Tsuji T, Watanabe S. Impact of calcification length ratio on the intervention for chronic total occlusions. Int J Cardiol. 2011;150(2):135-41.

25. Windecker S, Kolh P, Alfonso F, Collet JP, Cremer J, Falk V, Filippatos G, Hamm C, Head SJ, Juni P, et al. 2014 ESC/EACTS Guidelines on myocardial revascularization: The Task Force on Myocardial Revascularization of the European Society of Cardiology (ESC) and the European Association for Cardio-Thoracic Surgery (EACTS)Developed with the special contribution of the European Association of Percutaneous Cardiovascular Interventions (EAPCI). Eur Heart J. 2014;35(37):2541-619.

26. Mintz GS, Nissen SE, Anderson WD, Bailey SR, Erbel R, Fitzgerald PJ, Pinto FJ, Rosenfield K, Siegel RJ, Tuzcu EM et al. American College of Cardiology Clinical Expert Consensus Document on Standards for Acquisition, Measurement and Reporting of Intravascular Ultrasound Studies (IVUS). A report of the American College of Cardiology Task Force on Clinical Expert Consensus Documents. J Am Coll Cardiol. 2001;37(5):1478-92.

27. Thygesen K, Alpert JS, Jaffe AS, Simoons ML, Chaitman BR, White HD, Katus HA, Apple FS, Lindahl B, Morrow DA et al. Third universal definition of myocardial infarction. J Am Coll Cardiol. 2012;60(16):1581-98. 
28. Song HG, Kang SJ, Ahn JM, Kim WJ, Lee JY, Park DW, Lee SW, Kim YH, Lee CW, Park SW et al. Intravascular ultrasound assessment of optimal stent area to prevent in-stent restenosis after zotarolimus-, everolimus-, and sirolimus-eluting stent implantation. Catheter Cardiovasc Interv. 2014:83(6):873-8.

29. Palmer ND, Nair RK, Ramsdale DR. Treatment of calcified ostial disease by rotational atherectomy and adjunctive cutting balloon angioplasty prior to stent implantation. Int J Cardiovasc Intervent. 2004;6(3-4):134-6.

Submit your next manuscript to BioMed Central and we will help you at every step:

- We accept pre-submission inquiries

- Our selector tool helps you to find the most relevant journal

- We provide round the clock customer support

- Convenient online submission

- Thorough peer review

- Inclusion in PubMed and all major indexing services

- Maximum visibility for your research

Submit your manuscript at www.biomedcentral.com/submit 